\title{
Upper Airway Cough Syndrome in Pathogenesis of Chronic Cough
}

\author{
Miroslava LUCANSKA ${ }^{1}$, Andrej HAJTMAN ${ }^{1}$, Vladimir CALKOVSKY ${ }^{1}$, Peter KUNC ${ }^{2}$, \\ Renata PECOVA ${ }^{3}$
}

${ }^{1}$ Clinic of Otorhinolaryngology and Head and Neck Surgery, Jessenius Faculty of Medicine in Martin, Comenius University in Bratislava, University Hospital in Martin, Martin, Slovak Republic, ${ }^{2}$ Clinic of Pediatric Respiratory Diseases and Tuberculosis in National Institute of Pediatric Tuberculosis and Respiratory Diseases in Dolny Smokovec, Jessenius Faculty of Medicine in Martin, Comenius University in Bratislava, ${ }^{3}$ Department of Pathological Physiology, Jessenius Faculty of Medicine in Martin, Comenius University in Bratislava, Martin, Slovak Republic

Received September 6, 2019

Accepted October 7, 2019

\begin{abstract}
Summary
Cough is one of the most important defensive reflexes. However, extensive non- productive cough is a harmful mechanism leading to the damage of human airways. Cough is initiated by activation of vagal afferents in the airways. The site of their convergence is particularly the nucleus of the solitary tract (nTS). The secondorder neurons terminate in the pons, medulla and spinal cord and there is also the cortical and subcortical control of coughing. Upper airway cough syndrome (UACS) - previously postnasal drip syndrome - is one of the most common causes of chronic cough together with asthma and gastroesophageal reflux. The main mechanisms leading to cough in patients with nasal and sinus diseases are postnasal drip, direct irritation of nasal mucosa, inflammation in the lower airways, upper airway inflammation and the cough reflex sensitization. The cough demonstrated by UACS patients is probably due to hypersensitivity of the upper airways sensory nerve or lower airways sensory nerve, or a combination of both. Further studies are needed to clarify this mechanism.
\end{abstract}

\section{Key words}

Cough • Chronic cough • Upper airway cough syndrome

\section{Corresponding author}

R. Pecova, Comenius University in Bratislava, Jessenius Faculty of Medicine in Martin, Department of Pathological Physiology, Malá Hora 4C, 03601 Martin, Slovak Republic. E-mail: renata.pecova@uniba.sk

\section{Introduction}

Cough is a defensive respiratory reflex that begins with a brief inspiration, followed by expiration against a closed glottis which produces large increases in intrapulmonary pressures such that the final phase of opening of glottis evokes a large expulsive airflow for clearing the airways (Korpas and Tomori 1979, Mazzone and Undem 2016). Under normal conditions, cough serves an important protective role in the airways and lungs. However, cough is also a mechanism for the spread of lifethreatening respiratory tract infections. Furthermore, in diseases such as asthma, chronic obstructive pulmonary disease (COPD), gastroesophageal reflux disease (GERD), and rhinosinusitis, cough may become excessive and harmful to the airway mucosa and adversely impact patient quality of life (Canning et al. 2014). Cough can either occur reflexively (depending on afferent inputs processed at the brainstem level) or behaviorally (requiring higher brain cortical processing) (Narula et al. 2014).

\section{Peripheral and central mechanisms of cough}

Reflexive coughing is initiated by activation of mechanically and chemically sensitive vagal afferent nerves innervating the airways (Canning et al. 2006). The vagal sensory neurons are situated in two distinct ganglia - the nodose ganglion and the jugular ganglion (Mazzone and Undem 2016). Cough reflex is also modulated by many other afferent inputs within the vagus nerve and out of it. This modulation is called 'cough plasticity' (Canning and Mori 2011). There are different kinds of vagal afferent 
fiber subtypes, depending on how they respond to different stimuli (Grace et al. 2013, Mazzone and Canning 2016). The sensory nerve fibers terminate in and under the airway epithelium and detect the irritant signals coming into the airways and get activated (Song et al. 2014).

The recognition of chemical irritants and endogenous inflammatory mediators is mostly mediated by unmyelinated C-fibers (Song et al. 2014), that comprise the majority of afferent nerves innervating the airways (Mazzone and Undem 2016). C-fibers are often subclassified as pulmonary C-fibers or bronchial C-fibers, depending on whether the terminations receive blood supply from the pulmonary or bronchial circulation, respectively (Mazzone and Undem 2016). C-fibers are sensitive to a wide variety of inhaled or locally produced chemical mediators, including capsaicin (Canning et al. 2014). A C-fiber is termed "bronchial" if it is located in the large airways or if it responds with short latency to a chemical stimulant injected directly into the systemic circulation, i.e., into the bronchial artery. Pulmonary Cfibers are thought to terminate largely in the lung interstitium close to the pulmonary capillaries (Mazzone and Undem 2016). The sensation of mechanical stimuli is mainly mediated by myelinated A $\delta$ cough receptors; it is also responsive to rapid change in $\mathrm{pH}$ (Canning et al. 2006). The cough receptor terminations are found exclusively in the extrapulmonary airways (Canning et al. 2014). Lung stretch receptors are exclusively derived from the nodose ganglia and are classically identified as either rapidly (RAR) or slowly (SAR) adapting airway mechanoreceptors (Narula et al. 2014). These receptors mainly terminate in the intrapulmonary airways and are thought of as being less involved in cough reflex (Grace $e t$ al. 2013). Although C-fibers and the cough receptors subserve primary roles in cough initiation, all afferent nerve subtypes innervating the airways can modulate the cough reflex (Canning et al. 2006).

The central projections of all vagal afferents terminate in the brainstem where they innervate secondorder neurons that project to other brainstem nuclei, ascend to higher brain regions, or descend to the spinal cord (Mazzone and Undem 2016). The site of the convergence of vagal afferents is particularly the nucleus of the solitary tract (nTS) (Canning et al. 2014). However, recent studies suggest, that a substantial portion of airway sensory inputs also terminate in a region of the trigeminal nucleus known as the paratrigeminal nucleus (Pa5) (Narula et al. 2014). Second order neurons in the pathways from these receptors project to neurons located in respiratory-related regions of the medulla, pons and spinal cord (Kubin et al. 2006). However, there is also a higher brain control of coughing, that can manifest as inhibition of coughing or as voluntary cough. Also the urge to cough evoked by capsaicin inhalation is encoded in a brain network (Canning et al. 2014).

Many experiments have been performed to identify the central structures responsible for the formation and modulation of cough and other respiratory reflexes (Korpas and Tomori, 1979, Jakus et al. 1987, Jakus et al. 2000, Poliacek et al. 2003, Chen et al. 2017, Chen et al. 2019, Ji et al. 2018).

\section{Chronic cough}

Chronic cough in adults is broadly defined as cough persisting for more than 8 weeks (Morice et al. 2007). Most common causes of chronic cough are asthma, gastroesophageal reflux disease and upper airway cough syndrome (previously known as postnasal drip syndrome), collectively known as 'diagnostic triad of chronic cough' (Morice et al. 2007). Cough is not always related to another disease condition (Song and Morice 2017). $12-42 \%$ of patients did not fit into any categories despite vigorous diagnostic and therapeutic efforts. Cough in this group of patients was named idiopathic or refractory cough (McGarvey 2008).

In 2006, the American College of Chest Physicians (ACCP) defined upper airway cough syndrome (UACS), previously referred to as postnasal drip syndrome (PNDS), as one of several critical pathogeneses of chronic cough (Irwin et al. 1998, Pratter 2006). In UACS patients, cough can be caused by a variety of upper respiratory disorders, including nasal and sinus diseases. It can also result from anatomic abnormalities and physically- or chemically-induced rhinitis, as well as pharyngeal diseases (Yu et al. 2015). UACS/PNDS is the most common cause of chronic cough in the USA (Pratter 2006). Although UACS/PNDS has been proposed as a specific syndrome for more than 100 years and become a severe clinical problem, knowledge concerning its pathogenesis and management has remained inconsistent across different countries (Yu et al. 2015).

The pathogenesis of UACS/PNDS is unclear but there are several possible mechanisms:

\section{Postnasal drip}

In the past, chronic cough from UACS/PNDS was considered to result from postnasal drip-inducing 
mechano- or chemostimulation of the afferent nerves innervating the pharynx, larynx, or lower airways (Pratter 2006, Yu et al. 2015). PNDS causes the stimulation of cough receptors located in the hypopharynx or larynx by secretions emanating from the nose and/or sinuses dripping down into these areas (Pratter 2006). However, there are many arguments against this hypothesis. There seems to be considerable variance in the prevalence of postnasal drip among patients with chronic cough (Canning 2014). Postnasal drip is a physiologic finding (O'Hara and Jones 2006) and is not of itself an adequate explanation. Approximately $20 \%$ of patients with PNDSinduced cough are unaware of either the presence of PNDS or its link to their cough (Pratter 2006). Due to this uncertain causal relationship, starting in 2006, the ACCP has used the term UACS to replace PNDS (Pratter 2006).

\section{Direct irritation of nasal mucosa}

Nasal afferents express various ion channels and detect different kinds of stimuli. Terminals of the trigeminal afferents innervating nasal mucosa are commonly called 'gate-keepers', since these fibers are the first to detect substances entering the upper respiratory tract (Panneton et al. 2010). Direct stimulation of the nasal mucosa does not initiate cough (Canning et al. 2014), though, cough seems to be both up-regulated and downregulated by distinct populations of nasal afferents (Buday et al. 2012).

The TRPV1 agonists (capsaicin, histamine) and TRPA1 agonists (air born pollutants, oxidizing substances, and endogenous inflammatory products) evoke painful and noxious sensations and reflexes, TRPM8 activation by menthol, eucalyptol or camphor is soothing, a counterirritant to effects evoked by nociceptors (Canning 2014, Buday et al. 2012, Plevkova and Song 2013). The nasal stimulation by water also down-regulates the cough reflex in animal models (Poussel et al. 2012). There is a hypothesis that cough reflex is up-regulated during stimulation of nasal afferents in order to minimize the spreading of the pathological process from the nasal cavity to other parts of the respiratory tract (Plevkova and Song 2013). The trigeminal afferent pathways can promote the likelihood of cough by lowering the threshold of the central cough pattern generator to subsequent vagal afferent input, perhaps to the point where even innocuous or physiologic stimuli arising from the lower airways could promote coughing (Canning 2014). The sensitization of cough by the nasal trigeminal sensory pathways is perhaps more complex than the vagally- mediated sensitization since the trigeminal and the coughtriggering vagal sensory nerves terminate in different areas of the brainstem (Tatar et al. 2009). Although the primary sensory fibers from the nasal cavity are interpolated to second order neurons mainly in the sensitive nucleus of trigeminal nerve, these afferents have connections to the chemosensitive areas such as the area postrema, and also nTS, which may interfere with modulation of inputs to "cough generator" (Plevkova and Song 2013). The nasal trigeminal afferent stimulation also induced c-fos expression in the nTS, indicating the potential contribution of upper airway neurogenic inflammation in central sensitization of cough (Plevkova et al. 2010).

\section{Airway inflammation - lower airway inflammation}

Studies have shown that lower airway inflammation is commonly associated with chronic cough (Yu et al. 2015). Multiple inflammatory mediators, including histamine and prostaglandins, can increase the sensibility of cough via stimulating local nerve endings in the lower airways (Birring et al. 2004).

Furthermore, numerous studies have shown that airway inflammation in patients with non-asthmatic chronic cough, including patients with UACS, is mainly due to infiltration of mast cells, neutrophils, and lymphocytes, which is different from the etiologies associated with cough-variant asthma and eosinophilic bronchitis (Birring et al. 2004).

Patients with UACS showed a remodeling of the airways, characterized by increased sub-basement membrane thickness, vascularity, vessel size, and signs of goblet cell hyperplasia. The submucosal infiltration of mast cells in patients with non-asthmatic cough differed from the infiltration of eosinophils and neutrophils found in patients with asthmatic chronic cough. It was suggested that the airway structural changes or remodeling phenomena were the results of long-term airway inflammation (Niimi 2011). Airway inflammation could be a cause of increased cough sensitivity (Brozmanova et al. 2006, Pecova et al. 2008, Brozmanova et al. 2012).

One possible cause of lower airway inflammation is postnasal drip. Although most of the secretions do not enter the lower airways, older individuals and patients with cerebrovascular disease often have an impaired local swallowing reflex, and are susceptible to aspiration pneumonia. Therefore, one cannot exclude the possibility that an early stage of airway inflammation caused by aspiration might lead to increased cough sensitivity ( $\mathrm{Yu}$ et al. 2015). 
A second possible cause of airway inflammation is a mechanical stimulation. Some scholars believe that cough, as a repeated mechanical/physical stimulus, can damage airway mucosa and either cause or aggravate airway inflammation. This mechanical/physical stimulation might induce the airway epithelium to release multiple growth factors such as transforming growth factor b2, epidermal growth factor (Irwin et al. 2006), and nerve growth factor, all of which are correlated with the upregulation of transient receptor potential vanilloid 1 (TRPV1) expression and increased cough sensitivity (Yu et al. 2015).

The model of induced airway collapse was developed, and such mechanical stimulation produced an increased number of neutrophils in the airways and also increased cough reflex sensitivity. This directly proved that cough can cause neutrophil involved airway inflammation via mechanical stimulation (Hara et al. 2008).

Airway inflammation may also exist as a localized manifestation of a systemic inflammatory response. It is well-known that some rhinitis patients, and especially those suffering from allergic rhinitis, have atopic manifestations such as increased serum $\operatorname{IgE}$ levels, positive intracutaneous test results, and eosinophilia in blood and sputum, which are associated with genetic factors (Wang 2011). In these patients, airway inflammation might exist as a local manifestation of a systemic inflammatory response. However, whether the inflammation is a cause or an effect of the chronic cough should be elucidated in future studies (Niimi 2011).

\section{Airway inflammation - upper airway inflammation}

UACS is not only associated with nasal diseases but might also be influenced by chronic inflammation in the pharynx or larynx, such as inflammations resulting from allergic pharyngitis and chronic tonsillitis ( $\mathrm{Yu}$ et al. 2015). Such inflammations may result from long-term contact with nasal or sinus secretions. Currently, only a few clinical data has suggested that chronic tonsil hypertrophy in adults and children may be associated with cough that could be relieved or terminated following tonsillectomy (Birring et al. 2004b). Additional clinical studies are required to confirm the relationship between chronic cough and other diseases of the pharynx or larynx (Pratter 2006).

\section{Cough reflex sensitization}

There is increased cough sensitivity in allergic rhinitis patients without cough compared to sensitivity in healthy controls, and this difference was especially prominent during the pollen allergy season (Pecova et al. 2008). Individuals with increased cough sensitivity are more easily impacted by internal and external environmental tussive stimuli or show increased intensity of pre-existing cough. Thus, increased cough sensitivity as seen in allergic rhinitis patients may be one of the mechanisms that cause cough in UACS patients (Pecova et al. 2008). Histamine is an important inflammatory mediator and directly stimulates sensory neurons. Capsaicin activates local nerves via interacting with TVPR1 in nerve endings (Tatar et al. 2009). Although nasal inhalation of histamine or capsaicin does not produce cough in healthy controls or allergic rhinitis patients, it can increase cough sensitivity. Studies have shown that following stimulation of nasal sensory nerves with histamine or capsaicin, cough can be evoked by the oral inhalation of a certain concentration of aerosolized capsaicin (Plevkova et al. 2006).

The number of coughs increased by $60-100 \%$ in a nasal stimulated group compared with a healthy control group, and similar results were obtained when studying healthy individuals, allergic rhinitis patients, or a guinea pig model. Moreover, the degree of inflammation found in the nasal mucosa was positively correlated with the presence of rhinitis-induced cough (Brozmanova et al. 2007, Tatar et al. 2009). These studies verified that stimulation of nasal nerves might be the cause of elevated cough sensitivity. The mechanism of nasal neural activation-elicited increased cough sensitivity is not clear. After detection of an external stimulus, the nasal mucosa produces a variety of inflammatory factors such as histamine. These factors stimulate nasal sensory nerves and also the nasociliary nerve of the trigeminal nerve, which conducts signals to the nucleus of the spinal trigeminal tract. The central area, which accepts the projection of the vagus nerve, is the nucleus of the solitary tract (nTS) (Yu et al. 2015). To determine whether there was cross-over between these two pathways, capsaicin was used to stimulate the nasal mucosa of guinea pigs, and, when compared with control animals, found increased expression of c-fos in both the brainstem nTS and trigeminal nerve. c-fos is expressed when activated neurons generate action potentials, indicating that neurons in two different locations are both activated. It is speculated that in upper airway diseases, different central parts interact to influence the generation of cough through stimulation of nasal nerves (Plevkova and Song 2013). 
Therefore, it is hypothesized that environmental stimuli elicit inflammation of the nasal mucosa, resulting in signals being transmitted to the nucleus of the spinal trigeminal tract, and partially to the nTS through the local trigeminal nerve. The nTS might also be activated by a discharge of neurons in the nucleus of the spinal trigeminal tract, which in turn, will signal the vagus nerve in the lower airways mucosa to generate neurogenic inflammation, resulting in increased cough sensitivity ( $\mathrm{Yu}$ et al. 2015).

A constant postnasal drip can stimulate long-term chronic inflammation in the pharynx or larynx, resulting in localized inflammatory manifestations such as red and swollen mucosa, however, it is not clear if postnasal drip causes increased local sensitivity. Cough sensitivity was decreased in UACS patients, rhinitis/rhinosinusitis patients without cough, and healthy controls following local anesthesia of nerve endings in the pharynx and larynx by lidocaine (Yu et al. 2013). While there were no differences in the extent of the decreases, UACS patients still showed higher cough sensitivity than the other two groups following local anesthesia. These data suggest that although cough receptors in the larynx were probably involved in the heightened cough sensitivity shown by UACS patients, local sensitivity was not significantly higher than in the other two groups, and was not the main cause of cough. Instead, stimulation of lower respiratory cough receptors to an excited state may have been the main cause for the increased cough sensitivity in UACS patients (Yu et al. 2013).

\section{Cough hypersensitivity syndrome}

Concept of cough hypersensitivity syndrome (CHS) was proposed and suggested that the majority of patients with chronic cough can be incorporated into this syndrome (Morice 2010). Cough hypersensitivity syndrome is defined as a clinical entity characterized by cough as a major component, which is often triggered by low levels of thermal, mechanical, or chemical exposure (Song and Morice 2017). Patients with CHS usually present with one of three different phenotypes: (1) patients with a predominant phenotype of rhinal symptoms (such as UACS), (2) patients with a Th2-cell dominant phenotype (cough variant asthma or nonasthmatic eosinophilic bronchitis), and (3) patients with a predominant phenotype characterized by acid reflux and heartburn (chronic cough caused by gastroesophageal reflux) (Morice 2010). Cough hypersensitivity is demonstrated either as the lowered intensity of a stimulus required to trigger cough or as enhanced coughing in response to a stimulus with the constant intensity. The increased sensory nerve sensitivity allowed even a minimal stimulation to cause a cough, which was included in the category of sensory neuropathy (Chung et al. 2013). It has been demonstrated that the pathological change associated with both sensory hyperreactivity and cough hypersensitivity is the up-regulation of TRPV1 expression in sensory nerves and that TRPV1 antagonists are effective for improving the symptoms of sensory hyperreactivity and decreasing cough sensitivity (Gibson and Ryan 2011, Khalid et al. 2014). There is some evidence that suggests that the sensitivity of the cough reflex is higher in patients with UACS-induced cough (Pratter 2006). The sensitization of the cough reflex can be demonstrated as the lowered intensity of a stimulus required to trigger cough or enhanced coughing in response to a stimulus with the constant intensity (Tatar $e t$ al. 2009). Chronic nasal symptoms attributable to sensory nerve activation in patients with rhinitis implicate that the inflammation leads to repeated activation of sensory nerves. The repeated activation and mediators associated with inflammation in patients with rhinitis can induce sensitization at multiple levels of sensory pathways (Tatar et al. 2009) and may lead to altered central neural processing in cough control (Song and Morice 2017). In a guinea pig experiment, intranasal parainfluenza-3 virus infection significantly increased transient receptor potential vanilloid-1 (TRPV1) expression in tracheal nodose A $\delta$ neurons. These neuronal phenotypic switches are significantly correlated with cough responses to tussigens, such as capsaicin and citric acid, and have also been associated with increased expression of neurotrophic factor receptors in the neurons (Zaccone et al. 2016).

Allergic rhinitis is one of the most common causes of UACS - induced cough (Pratter 2006). Inflammatory mediators, neurotrophic factors and other signals emanating from the nose during the symptomatic period could, in theory, initiate long-lasting neural plastic changes in the circuits regulating the cough reflex (Tatar et al. 2009). The sensitization of the cough reflex also lasts in subjects without the pollen season (Pecova et al. 2008). Mechanistically, it is suggested that allergic rhinitis modulates two distinct types of cough-either cough induced by stimulation of putative TRPV1-expressing capsaicin-sensitive fibers, or cough initiated by capsaicininsensitive mechanosensitive A $\delta$ nodose fibers (Plevkova and Song 2013). 


\section{Conclusion}

Cough reflex is a vital defensive reflex. In some disease conditions, including upper airway diseases, a state of hypersensitivity is created. Cough hypersensitivity syndrome is still a conceptual entity. However, accumulating evidence supports the notion that neuropathology is the key pathophysiology underlying this syndrome (Song and Morice 2017). The cough hypersensitivity during infections may be a protective strategy to prevent the spread of diseases from upper respiratory tract to other parts but this mechanism also leads to excessive distressing coughing. The cough demonstrated by UACS patients is probably due to hypersensitivity of the upper airways sensory nerve or lower airways sensory nerve, or a combination of both. Further studies are needed to clarify this mechanism.

\section{Conflict of Interest}

There is no conflict of interest.

\section{Acknowledgements}

This work was supported by the project of Ministry of Health of the Slovak Republic 2018/12-UKMT-8.

\section{References}

BIRRING SS, PARKER D, BRIGHTLING CE, BRADDING P, WARDLAW AJ, PAVORD ID: Induced sputum inflammatory mediator concentrations in chronic cough. Am J Respir Crit Care Med 169: 15-19, 2004. https://doi.org/10.1164/rccm.200308-10920C

BIRRING SS, PASSANT C, PATEL RB, PRUDON B, MURTY GE, PAVORD ID: Chronic tonsillar enlargement and cough: preliminary evidence of a novel and treatable cause of chronic cough. Eur Respir J 23: 199-201, 2004b. https://doi.org/10.1183/09031936.03.00066403

BROZMANOVA M, BARTOS V, PLANK L, TATAR M: Experimental allergic rhinitis-related cough and airway eosinophilia in sensitized guinea pigs. J Physiol Pharmacol 58 (Suppl 5): 57-65, 2007.

BROZMANOVA M, CALKOVSKY V, PLEVKOVA J, BARTOS V, PLANK L, TATAR M: Early and late allergic phase related cough response in sensitized guinea pigs with experimental allergic rhinitis. Physiol Res 55: 577$584,2006$.

BROZMANOVA M, MAZUROVA L, RU F, TATAR M, KOLLARIK M: Comparison of TRPA1-versus TRPV1mediated cough in guinea pigs. Eur J Pharmacol 689: 211-218, 2012. https://doi.org/10.1016/j.ejphar.2012.05.048

BUCCA CB, BUGIANI M, CULLA B, GUIDA G, HEFFLER E, MIETTA S, MORETTO A, ROLLA G, BRUSSINO L: Chronic cough and irritable larynx. J Allergy Clin Immunol 127: 412-419, 2011. https://doi.org/10.1016/j.jaci.2010.10.038

BUDAY T, BROZMANOVA M, BIRINGEROVA Z, GAVLIAKOVA S, POLIACEK I, CALKOVSKY V, SHETTHALLI MV, PLEVKOVA J: Modulation of cough response by sensory inputs from the nose - role of trigeminal TRPA1 versus TRPM8 channels. Cough 8: 11, 2012. https://doi.org/10.1186/1745-9974-8-11

CANNING BJ, CHANG AB, BOLSER DC, SMITH JA, MAZZONE SB, MCGARVEY L: Anatomy and neurophysiology of cough: CHEST Guideline and Expert Panel report. Chest 146: 1633-1648, 2014. https://doi.org/10.1378/chest.14-1481

CANNING BJ, MORI N, MAZZONE SB: Vagal afferent nerves regulating the cough reflex. Respir Physiol Neurobiol 152: 223-242, 2006. https://doi.org/10.1016/j.resp.2006.03.001

CANNING BJ, MORI N: Encoding of the cough reflex in anesthetized guinea pigs. Am J Physiol Regul Integr Comp Physiol 300: 369-377, 2011. https://doi.org/10.1152/ajpregu.00044.2010

CHEN Z, GU D, SUN L, ZHANG W, FAN L, LIN Y, DONG R, LAI K: Neuronal activity of the medulla oblongata revealed by manganese-enhanced magnetic resonance imaging in a rat model of gastroesophageal reflux-related cough. Physiol Res 68: 119-127, 2019 https://doi.org/10.33549/physiolres.933791

CHEN Z, CHEN H, CHEN F, GU D, SUN L, ZHANG W, FAN L, LIN Y, DONG R, LAI K: Vagotomy decreases the neuronal activities of medulla oblongata and alleviates neurogenic inflammation of airways induced by repeated intra-esophageal instillation of $\mathrm{HCl}$ in guinea pigs. Physiol Res 66: 1021-1028, 2017. https://doi.org/10.33549/physiolres.933574 
CHUNG KF, MCGARVEY L, MAZZONE SB: Chronic cough as a neuropathic disorder. Lancet Respir Med 1: 414-422, 2013. https://doi.org/10.1016/S2213-2600(13)70043-2

ESCAMILLA R, ROCHE N: Cough hypersensitivity syndrome: towards a new approach to chronic cough. Eur Respir J 44: 1103-1106, 2014. https://doi.org/10.1183/09031936.00150614

GIBSON PG, RYAN NM: Cough pharmacotherapy: current and future status. Expert Opin Pharmacother 12:1745-1755, 2011. https://doi.org/10.1517/14656566.2011.576249

GRACE MS, DUBUIS E, BIRREL MA, BELVISI MG: Pre-clinical studies in cough research: role of Transient Receptor Potential (TRP) channels. Pulm Pharmacol Ther 26: 498-507, 2013. https://doi.org/10.1016/j.pupt.2013.02.007

HARA J, FUJIMURA M, UEDA A, MYOU S, ORIBE Y, OHKURA N: Effect of pressure stress applied to the airway on cough-reflex sensitivity in Guinea pigs. Am J Respir Crit Care Med 177: 585-592, 2008. https://doi.org/10.1164/rccm.200703-457OC

IRWIN RS, BOULET LP, CLOUTIER MM, FULLER R, GOLD PM, HOFFSTEIN V, ING AJ, MCCOOL FD, O'BYRNE P, POE RH, PRAKASH UB, PRATTER MR, RUBIN BK: Managing cough as a defense mechanism and as a symptom. A consensus panel report of the american college of chest physicians. Chest 114 (2 Suppl Managing): 133S-181S, 1998. https://doi.org/10.1378/chest.114.2_Supplement.133S

IRWIN RS, OWNBEY R, CAGLE PT, BAKER S, FRAIRE AE: Interpreting the histopathology of chronic cough: a prospective, controlled, comparative study. Chest 130: 362-370, 2006. https://doi.org/10.1378/chest.130.2.362

JAKUS J, TOMORI Z, STRÁNSKY A, BOSELOVÁ L: Bulbar respiratory activity during defensive airways reflexes in cats. Acta Physiol Hung 70: 245-254, 1987.

JAKUS J, STRANSKY A, POLIACEK I, BARANI H, BOSELOVA L: Kainic acid lesions to the lateral tegmental field of medulla: effects on cough, expiration and aspiration reflexes in anesthetized cats. Physiol Res 49: 387-398, 2000.

JI Z, WANG Z, CHEN Z, JIN H, CHEN C, CHAI S, LV H, YANG L, HU Y, DONG R, LAI K: Melatonin attenuates chronic cough mediated by oxidative stress via transient receptor potential melastatin-2 in guinea pigs exposed to particulate matter 2.5. Physiol Res 67: 293-305, 2018. https://doi.org/10.33549/physiolres.933654

KHALID S, MURDOCH R, NEWLANDS A, SMART K, KELSALL A, HOLT K, DOCKRY R, WOODCOCK A, SMITH JA: Transient receptor potential vanilloid 1 (TRPV1) antagonism in patients with refractory chronic cough: a double-blind randomized controlled trial. J Allergy Clin Immunol 134: 56-62, 2014. https://doi.org/10.1016/j.jaci.2014.01.038

KORPAS J, TOMORI Z: Cough and Other Respiratory Reflexes. Karger, Basel, 1979, p 356.

KUBIN L, ALHEID GF, ZUPERKU EJ, MCCRIMMON DR: Central pathways of pulmonary and lower airway vagal afferents. J Appl Physiol 101: 618-627, 2006. https://doi.org/10.1152/japplphysiol.00252.2006

MAZZONE SB, UNDEM BJ: Vagal afferent innervation of the airways in health and disease. Physiol Rev 96: 975-1024, 2016. https://doi.org/10.1152/physrev.00039.2015

MCGARVEY LP: Does idiopathic cough exist? Lung 186: 78-81, 2008. https://doi.org/10.1007/s00408-007-9048-4

MORICE AH: The cough hypersensitivity syndrome: a novel paradigm for understanding cough. Lung 188 (Suppl 1): S87-90, 2010. https://doi.org/10.1007/s00408-009-9185-z

MORICE AH, FONTANA GA, BELVISI MG, BIRRING SS, CHUNG KF, DICPINIGAITIS PV, KASTELIK JA, MCGARVEY LP, SMITH JA, TATAR M, WIDDICOMBE J: ERS guidelines on the assessment of cough. Eur Respir J 29: 1256-1276, 2007. https://doi.org/10.1183/09031936.00101006

NARULA M, MCGOVERN AE, YANG SK, FARRELL MJ, MAZZONE SB: Afferent neural pathways mediating cough in animals and humans. J Thorac Dis 6: 712-719, 2014. https://doi.org/10.3978/j.issn.2072-1439.2014.03.15

NIIMI A: Structural changes in the airways: cause or effect of chronic cough? Pulm Pharmacol Ther 24: 328-333, 2011. https://doi.org/10.1016/j.pupt.2011.01.011

O'HARA J, JONES NS: "Post-nasal drip syndrome": most patients with purulent nasal secretions do not complain of chronic cough. Rhinology 44: 270-273, 2006.

PANNETON WM, GAN Q, JURIC R: The rat: a laboratory model for studies of the diving response. J Appl Physiol 108: 811-820, 2010. https://doi.org/10.1152/japplphysiol.00600.2009

PECOVA R, ZUCHA J, PEC M, NEUSCHLOVA M, HANZEL P, TATAR M: Cough reflex sensitivity testing in seasonal allergic rhinitis patients and healthy volunteers. J Physiol Pharmacol 59: 557-564, 2008. 
PLEVKOVA J, POLIACEK I, ANTOSIEWICS J, ADAMKOV M, JAKUS J, SVIRLOCHOVA K, TATAR M: Intranasal TRPV1 agonist capsaicin challenge and its effect on c-fos expression in the guinea pig brainstem. Respir Physiol Neurobiol 173: 11-15, 2010. https://doi.org/10.1016/j.resp.2010.05.015

PLEVKOVA J, BROZMANOVA M, PECOVA R, TATAR M: The effects of nasal histamine challenge on cough reflex in healthy volunteers. Pulm Pharmacol Ther 19: 120-127, 2006. https://doi.org/10.1016/j.pupt.2005.04.004

PLEVKOVA J, SONG WJ: Chronic cough in subjects with upper airway diseases - analysis of mechanisms and clinical applications. Asia Pac Allergy 3: 127-135, 2013. https://doi.org/10.5415/apallergy.2013.3.2.127

POLIACEK I, STRANSKY A, JAKUS J, BARANI H, TOMORI Z, HALASOVA E: Activity of the laryngeal abductor and adductor muscles during cough, expiration and aspiration reflexes in cats. Physiol Res 52: 749-762, 2003.

POUSSEL M, VARECHOVA S, DEMOULIN B, CHALON B, SCHWEITZER C, MARCHAL F, CHENUEL B: Nasal stimulation by water down-regulates cough in anesthetized rabbits. Respir Physiol Neurobiol 183: 20-25, 2012. https://doi.org/10.1016/j.resp.2012.05.021

PRATTER MR: Chronic upper airway cough syndrome secondary to rhinosinus diseases (previously referred to as postnasal drip syndrome). Chest 129: 63-71, 2006. https://doi.org/10.1378/chest.129.1_suppl.63S

SONG WJ, MORICE AH: Cough hypersensitivity syndrome: a few more steps forward. Allergy Asthma Immunol Res 9: 394-402, 2017. https://doi.org/10.4168/aair.2017.9.5.394

SONG WJ, CHANG YS, MORICE AH: Changing the paradigm for cough: does 'cough hypersensitivity' aid our understanding? Asia Pac Allergy 4: 3-13, 2014. https://doi.org/10.5415/apallergy.2014.4.1.3

TATAR M, PLEVKOVA J, BROZMANOVA M, PECOVA R, KOLLARIK M: Mechanisms of the cough associated with rhinosinusitis. Pulm Pharmacol Ther 22: 121-126, 2009. https://doi.org/10.1016/j.pupt.2008.11.014

WANG DE Y: Genetic predisposition for atopy and allergic rhinitis in the Singapore Chinese population. Asia Pac Allergy 1: 152-156, 2011. https://doi.org/10.5415/apallergy.2011.1.3.152

YU L, XU X, WANG L, YANG Z, LU H, QIU Z: Capsaicin-sensitive cough receptors in lower airway are responsible for cough hypersensitivity in patients with upper airway cough syndrome. Med Sci Monit 19: 1095-1101, 2013. https://doi.org/10.12659/MSM.889118

YU L, XU X, LV H, QIU Z: Advances in upper airway cough syndrome. Kaohsiung J Med Sci 31: 223-228, 2015. https://doi.org/10.1016/j.kjms.2015.01.005

ZACCONE EJ, LIEU T, MUROI Y, POTENZIERI C, UNDEM BE, GAO P, HAN L, CANNING BJ, UNDEM BJ: Parainfluenza 3-induced cough hypersensitivity in the guinea pig airways. PLoS One 11: e0155526, 2016. https://doi.org/10.1371/journal.pone.0155526 